\title{
Implementasi Metode Trend Moment (Peramalan) Mahasiswa Baru Universitas Widyagama Malang
}

\author{
Ilyas $^{1}$, Fitri Marisa ${ }^{2}$, Dwi Purnomo ${ }^{3}$ \\ ${ }^{1}$ Ilyasshoky353@gmail.com, ${ }^{2}$ fitrimarisa@widyagama.ac.id, ${ }^{3}$ Purnomo_it@yahoo.com , \\ Program Studi Teknik Informatika, UniversitasWidyagama Malang
}

\begin{abstract}
Admission of a new student is one of the processes that exist in educational institutions such as universities that are useful for screening prospective students who are selected according to the criteria determined by the university. In general, the process of admission is done through the stages of registration, file selection and the announcement of student acceptance. Stage of the admissions process is also done by Universitas Widyagama Malang. Appropriate promotional methods and strategies are needed so that the number of students can increase every year, methods and strategies can be developed using new student data.
\end{abstract}

The Moment Trend method uses statistical and mathematical calculations. Moment trend method is a method of analysis that can be used for forecasting purposes by forming the equation $Y=a+b X$. The purpose of this research is to make Application of Trend Moment Method (Forecasting) of New student at Universitas Widyagama Malang. Forecasting application using trend moment method can be used to predict the number of a new student in Universitas Widyagama Malang in the next coming period and also this forecasting application can facilitate officers at the Universitas Widyagama Malang to detrmine and know the number of a new students who will come. This application has an accuracy of $\mathbf{9 8 . 2 5 \%}$

Abstrak-Penerimaan mahasiswa baru merupakan salah satu proses yang ada di instansi pendidikan seperti universitas yang berguna untuk menyaring calon mahasiswa yang terpilih sesuai kriteria yang ditentukan oleh universitas tersebut. Pada umumnya proses penerimaan mahasiswa baru dilakukan melalui tahapan pendaftaran, seleksi berkas, dan pengumuman penerimaan mahasiswa. Tahapan dari proses penerimaan mahasiswa baru ini juga dilakukan oleh Universitas Widyagama Malang. Metode dan strategi promosi yang tepat sasaran sangat dibutuhkan agar jumlah mahasiswa dapat bertambah setiap tahunnya. Metode dan strategi dapat disusun dengan memanfaatkan data mahasiswa baru.

Metode Trend Moment menggunakan cara-cara perhitungan statistika dan matematika. Metode Trend Moment merupakan metode analisis yang dapat digunakan untuk keperluan peramalan dengan membentuk persamaan $Y=a+b X$. Tujuan dari penelitian ini adalah membuat Implementasi Metode Trend Moment (Peramalan) Mahasiswa Baru di Universitas Widyagama Malang.

Aplikasi peramalan menggunakan metode trend moment dapat dipergunakan untuk meramalkan jumlah mahasiswa baru di Universitas Widyagama Malang di periode yang akan datang dan Juga aplikasi peramalan ini dapat mempermudah petugas di Universitas Widyagama Malang untuk menentukan dan mengetahui jumlah mahasiswa baru yang akan datang.

Kata Kunci: Trend moment, mahasiswa baru, peramalan

\section{PENDAHULUAN}

\section{A. Latar Belakang}

Sejalan dengan perkembangan ilmu pengetahuan dan teknologi saat ini, peranan pemanfaatan teknologi informasi sangatlah penting. Di mana dalam memperoleh atau mendapatkan suatu informasi yang akurat yang realisasinya akan dipakai untuk kelancaran usaha maupun dipakai sebagai acuan untuk membantu pimpinan dalam pengambilan keputusan[1]. Perkembangan teknologi yang kian pesat juga memicu perkembangan online untuk memberikan informasi maupun pelayanan yang prima secara efisien yang dipandang dari segi waktu, biaya, dan tenaga[2].

Penerimaan mahasiswa baru merupakan salah satu proses yang ada di instansi pendidikan seperti universitas yang berguna untuk menyaring calon mahasiswa yang terpilih sesuai kriteria yang ditentukan oleh universitas tersebut[3]. Pada umumnya proses penerimaan mahasiswa baru dilakukan melalui tahapan pendaftaran, seleksi berkas, dan pengumuman penerimaan mahasiswa. Tahapan dari proses penerimaan mahasiswa baru ini juga dilakukan oleh Universitas Widyagama Malang.

Metode dan strategi promosi yang tepat sasaran sangat dibutuhkan agar jumlah mahasiswa dapat bertambah setiap tahunnya[4]. Metode dan strategi dapat disusun dengan memanfaatkan data mahasiswa baru. Untuk itu dibutuhkan peran sebuah aplikasi peramalan yang dapat memprediksi jumlah mahasiswa baru yang akan masuk ke Universitas Widyagama Malang dari berbagai daerah. Dengan mengetahui prediksi jumlah mahasiswa baru pada periode yang akan 
datang, maka Universitas Widyagama Malang dapat merancang strategi promosi yang lebih efektif dan efisien. Banyak metode yang dapat digunakan dalam melakukan peramalan, salah satunya adalah Trend Moment.

Pada metode Trend Moment ini, terdapat gabungan dari analisis statistik berupa analisis trend dan metode moment [5]. Dalam penerapan metode Trend Moment, dapat di lakukan dengan menggunakandata historis dari satu variabel, adapun rumus yang digunakan dalam penyusunan dari metode $\mathrm{Y}=\mathrm{a}+$ b.X. Tujuan dari penelitian ini adalah membuat Implementasi Metode Trend Moment (Peramalan) Mahasiswa Baru di Universitas Widyagama Malang.

\section{TINJAUAN PUSTAKA}

\section{A. Peramalan}

Peramalan adalah data di masa lalu yang digunakan untuk keperluan estimasi data yang akan datang. Peramalan atau Forecasting merupakan bagian terpenting bagi setiap perusahaan ataupun organisasi bisnis dalam setiap pengambilan keputusan manajemen. Peramalan itu sendiri bisa menjadi dasar bagi perencanaan jangka pendek, menengah maupun jangka panjang suatu perusahaan. Ramalan pada dasarnya merupakan dugaan atau perkiraan mengenai terjadinya suatu kejadian atau peristiwa di waktu yang akan datang.

\section{B. Metode Trend Moment}

Sebuah sistem peramalan penjualan yang dapat membantu meminimalkan biaya dalam menyuplai barang yang akan dijual, karena dengan mengetahui beberapa penjualan pada periode yang akan datang, perusahaan dapat menyuplai barang secara tidak berlebihan[6]. Dalam penerapan metode Trend Moment dapat di lakukan dengan menggunakan data historis dari satu variabel, adapun rumus yang di gunakan dalam penyusunan dari metode ini adalah :

$$
\mathrm{Y}=\mathrm{a}+\mathrm{bX}
$$

Dimana :

$$
\begin{aligned}
& \mathrm{Y}=\text { nilai } \text { trend } \text { atau variabel yang akan diramalkan } \\
& \mathrm{a}=\text { bilangan konstan } \\
& \mathrm{b}=\text { slope atau koefisien garis } \text { trend } \\
& \mathrm{X}=\text { indeks waktu (dimulai dari } 0,1,2, \ldots . \mathrm{n})
\end{aligned}
$$

Untuk mencari nilai $a$ dan $b$ pada rumus diatas, digunakan dengan cara matematis dengan penyelesaiannya menggunakan metode subtitusi dan metode eliminasi.

Adapun persamaannya yaitu :

$\Sigma \mathrm{y}=\mathrm{a} . \mathrm{n}+\mathrm{b} . \Sigma \mathrm{x}$

$$
\begin{aligned}
& \Sigma \mathrm{xy}=\mathrm{a} \cdot \Sigma \mathrm{x}+\mathrm{b} \Sigma \mathrm{x} 2 \\
& \text { Dimana : } \\
& \Sigma \mathrm{y}=\text { jumlah dari data penjualan } \\
& \Sigma \mathrm{x}=\text { jumlah dari periode waktu }
\end{aligned}
$$

\section{Pengertian Mahasiswa}

Mahasiswa adalah seseorang yang sedang dalam proses menimba ilmu ataupun belajar dan terdaftar sedang menjalani pendidikan pada salah satu bentuk perguruan tinggi yang terdiri dari akademik, politeknik, sekolah tinggi, institut dan universitas. Dalam Kamus Bahasa Indonesia (KBI), mahasiswa didefinisikan sebagai orang yang belajar di Perguruan Tinggi (Kamus Bahasa Indonesia Online, kbbi.web.id)

Mahasiswa dapat didefinisikan sebagai individu yang sedang menuntut ilmu ditingkat perguruan tinggi, baik negeri maupun swasta atau lembaga lain yang setingkat dengan perguruan tinggi

\section{Calon Mahasiswa Baru}

Calon mahasiswa baru merupakan orang yang mendapat hak pedidikan ataupun skill di suatu perguruan tinggi dengan baik berdasarkan syarat-syarat yang telah ditentukan dari suatu instansi atau perguruan tinggi. Jumlah calon mahasiswa baru adalah banyaknya calon mahasiswa baru yang mendaftar di suatu perguruan tinggi baik perguruan tinggi negeri maupun swasta. Salah satu tujuan dari calon mahasiswa baru adalah untuk mendapatkan pendidikan yang baik di perguruan tinggi. Secara umum tujuan calon mahasiswa pada suatu perguruan tinggi adalah:
a. Mencerdaskan kehidupan bangsa
b. Mencapai volume dan hasil calon mahasiswa baru
c. Menunjang pertumbuhan perguruan tinggi.

\section{E. Flowchart}

Flowchart atau diagram alir merupakan sebuah diagram dengan simbol grafis yang menyatakan aliran algoritma atau proses yang menampilkan langkah-langkah yang disimbolkan dalam bentuk kotak, beserta urutannya dengan menghubungkan masing-masing langkah tersebut menggunakan tanda panah. Diagram ini bisa memberi solusi selangkah demi selangkah untuk penyelesaian masalah yang ada di dalam proses atau algoritma tersebut.

\section{F. Perancangan Sistem}

Perancangan sistem adalah diagram yang menggambarkan sistem yang sedang berjalan dan sistem baru yang akan digunakan dengan menggunakan komputer[7]. Dalam tahaptahap ini dilakukan pemecahan masalah secara logika dengan menggunakan alat bantu, yaitu DFD ( Data Flow Diagram ) dan ERD ( Entity Relationship Diagram )[8]. 


\section{METODE PENELITIAN}

\section{A. Analisis Sistem}

Dalam membangun sebuah Implementasi Metode Trend Moment (Peramalan) Mahasiswa Baru di Universitas Widyagama Malang. Dilakukan beberapa tahap analisis yaitu :

1. Menentukan masalah yang akan dibangun untuk sebuah aplikasi Implementasi Metode Trend Moment (Peramalan) Mahasiswa Baru di Universitas Widyagama Malang.

2. Mengumpulkan data yang diperlukan untuk membangun sistem, yaitu berupa informasi tentang jumlah mahasiswa.

\section{B. Perancangan Sistem}

1) Diagram Konteks

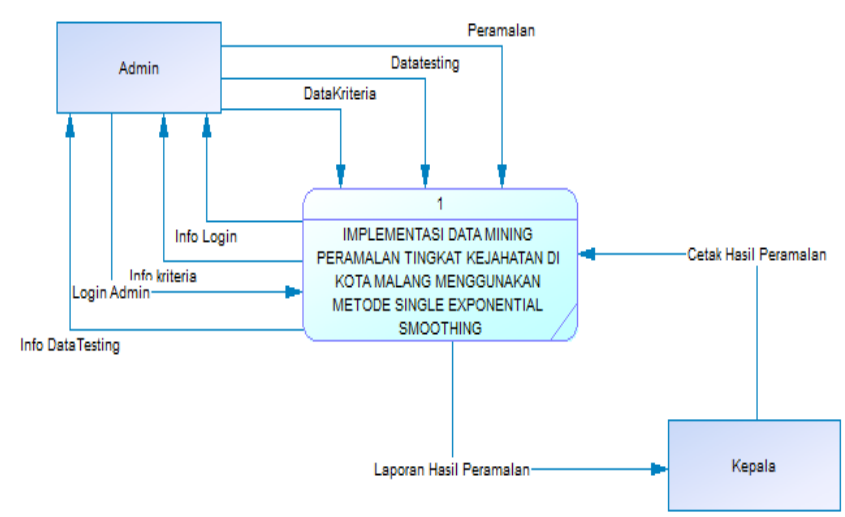

Gambar 1. DFD Level 1

\section{2) DFD Pengelolaan Master}

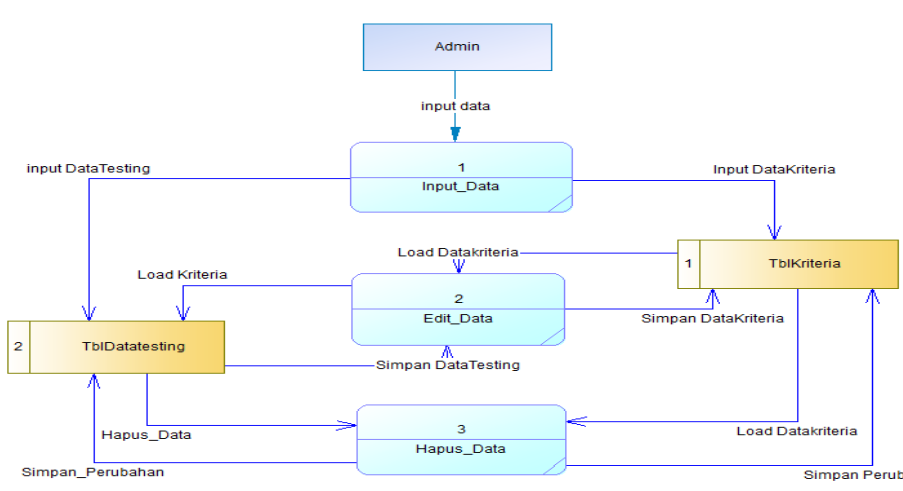

Gambar 2. DFD Level 2 pengolahan data master
3) DFD Level 2 Proses Analisa

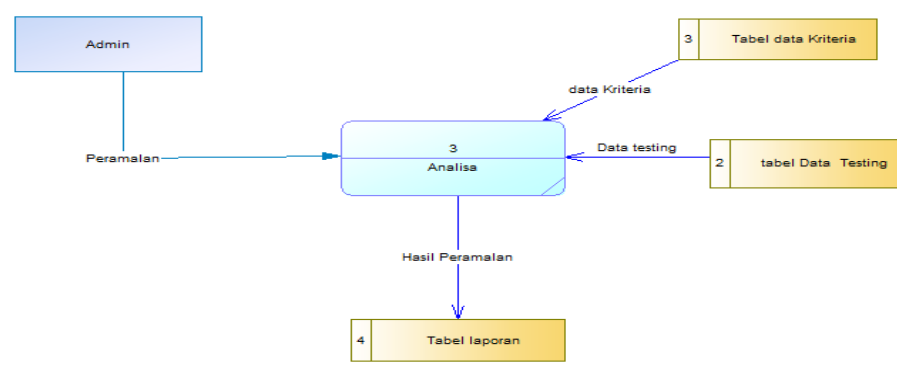

Gambar 3. DFD Level 2 Proses Analisa

4) DFD Level 2 Proses Laporan

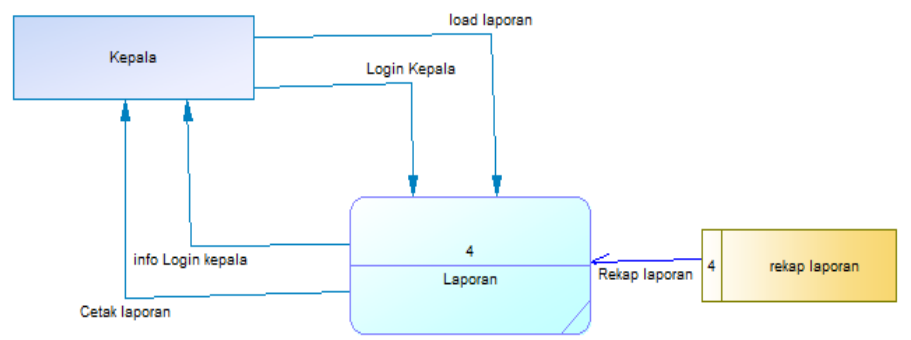

Gambar 4. DFD Level 2 Proses Laporan

\section{Perancangan Antar Muka}

Berikut ini adalah desain interface dari program Rancang Bangun Peramalan mahasiswa baru menggunakan trend moment.

\section{1) Form Menu}

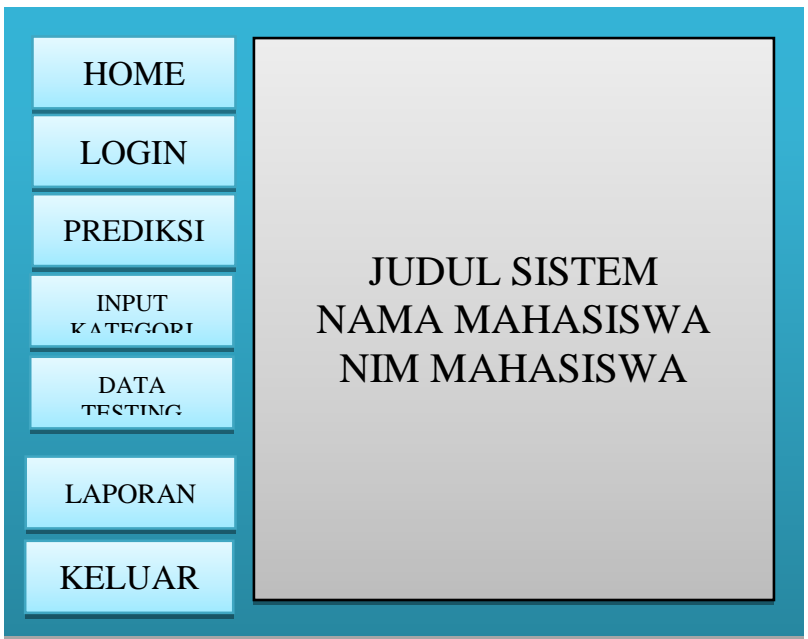

Gambar 5. Form menu 
2) Form Login

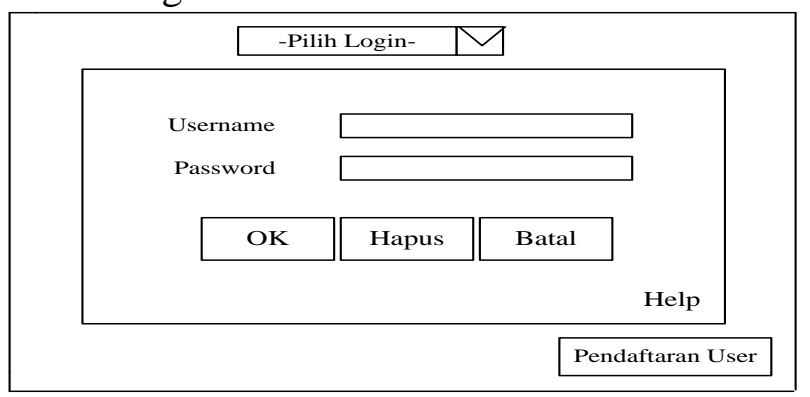

Gambar 6. Form login

3) Form Data Kriteria

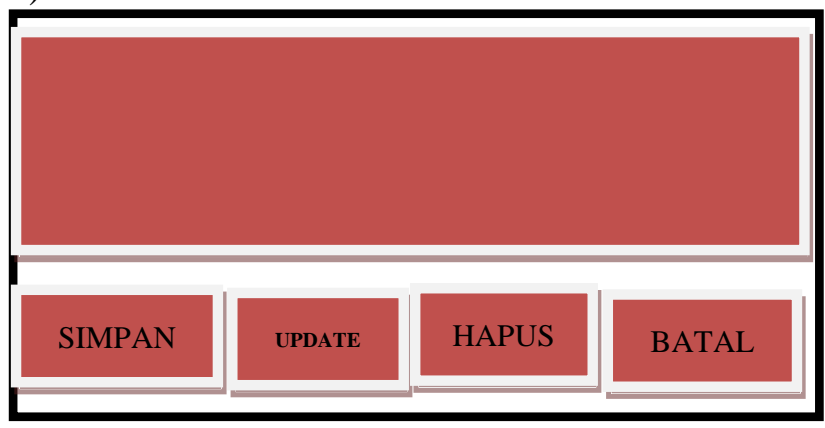

Gambar 7. Formdata kriteria

4) Form Data Peramalan

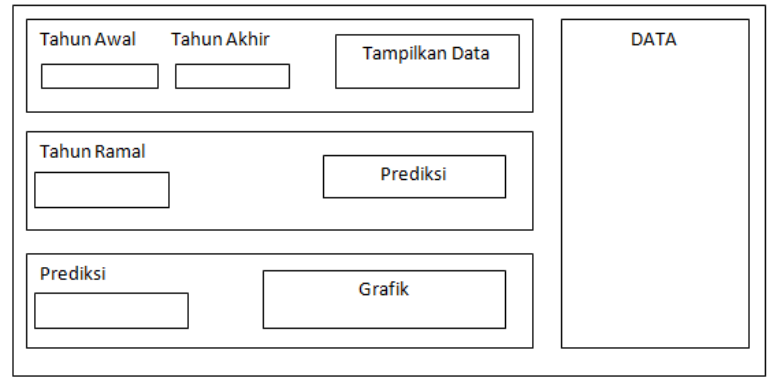

Gambar 8. Form data peramalan

\section{5) Form Laporan}

\begin{tabular}{||l|l|l|l|}
\hline \multicolumn{5}{|c|}{ REKAP LAPORAN } \\
\hline No & Kode & Tahun & Prediksi \\
\hline & & & \\
\hline & & & \\
\hline & & & \\
\hline & & & \\
\hline & & & \\
\hline & & & \\
\hline
\end{tabular}

Gambar 9. Laporan

\section{HASIL DAN PEMBAHASAN}

\section{A. Implementasi}

Implementasi sistem adalah prosedur yang dilakukan untuk menyelesaikan desain yang ada dalam dokumendesain sistem yang disetujui dan menguji, menginstal, memulai, serta menggunakan sistem yang baru atausistem yang diperbaiki.Penggunaan suatu komputer untuk pemecahan masalah membutuhkan suatu sistem yang baik, sehinggamemungkinkan berhasilnya komputer dalam melaksanakan tugasnya, yaitu mengolah data menjadi informasi.

1) Form halaman utama

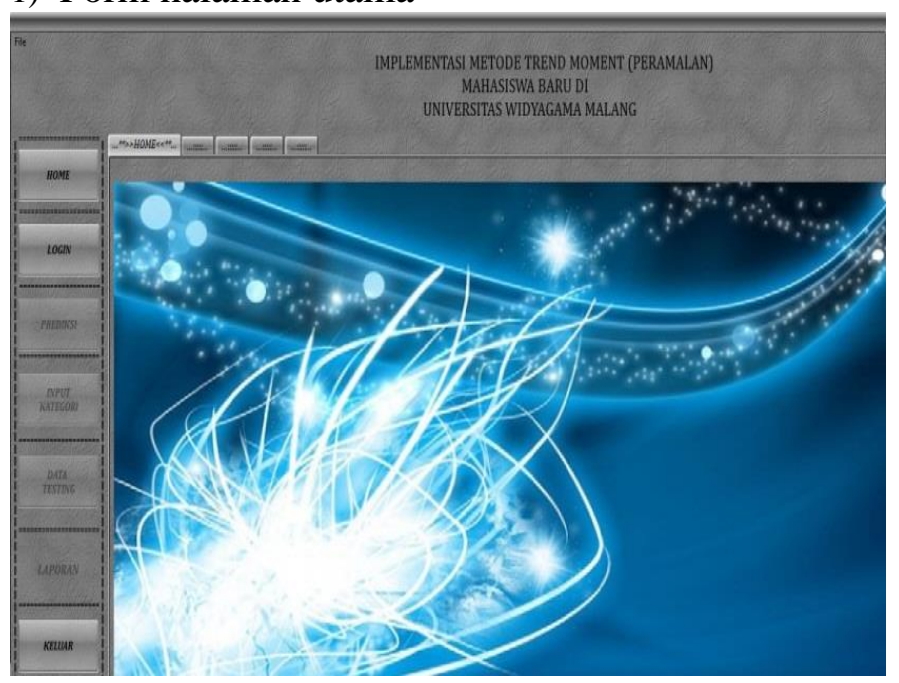

Gambar 10. Implementasi form halaman utama

Form halaman utama merupakan halaman pertama yang muncul saat pertama kali sistem dijalankan. Form halaman utama ini terdiri dari menu home, menu login, menu, menu prediksi, menu input kategori, menu data testing, menu laporan dan menu keluar.

\section{2) Form menu login admin}

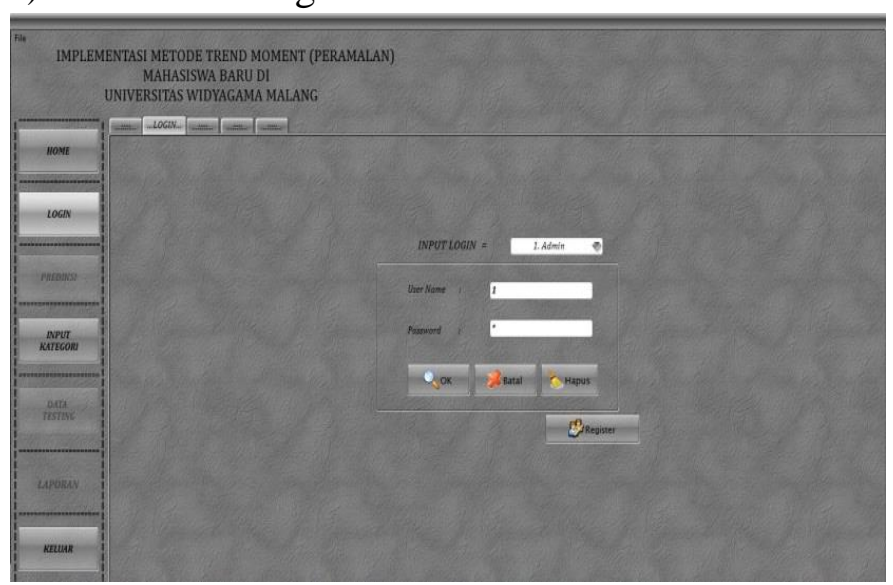

Gambar 11. Implementasi form menu login 
Form login dilakukan oleh admin dan kepala. Admi dan Kepala menginputkan username dan password yang sudah dimiliki. Setelah sukses login, admin dan kepala dapat masuk kedalam sistem.

\section{3) Form Input kategori}

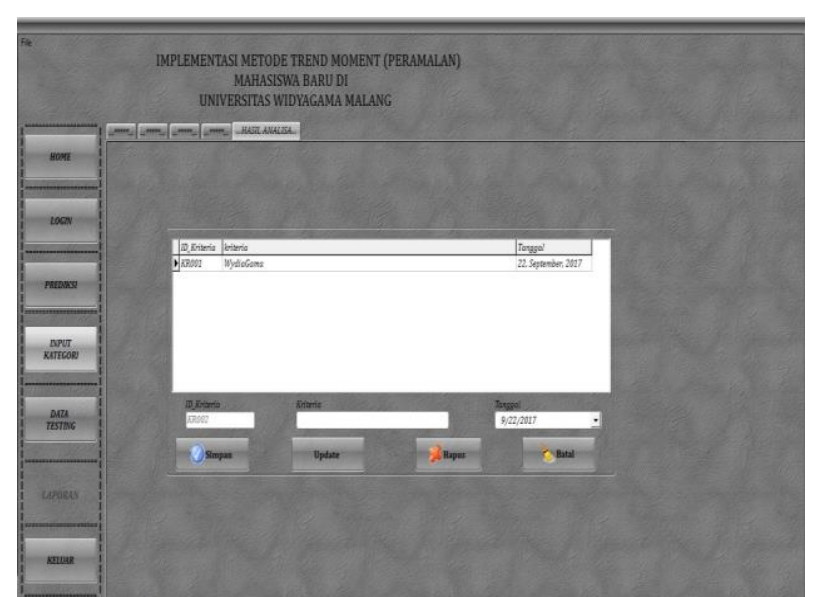

Gambar12. Implementasi form input kategori

Form ini menampilkan data testing menampilkan data-data jenis kejahatan dengan jumlah tingkat kejahatan. Data-data tersebut disimpan kedalam database. Didalam database ini dapat menyimpan data, mengupdate data, menghapus data, membatalkan data dan mencetak data.

4) Form data prediksi

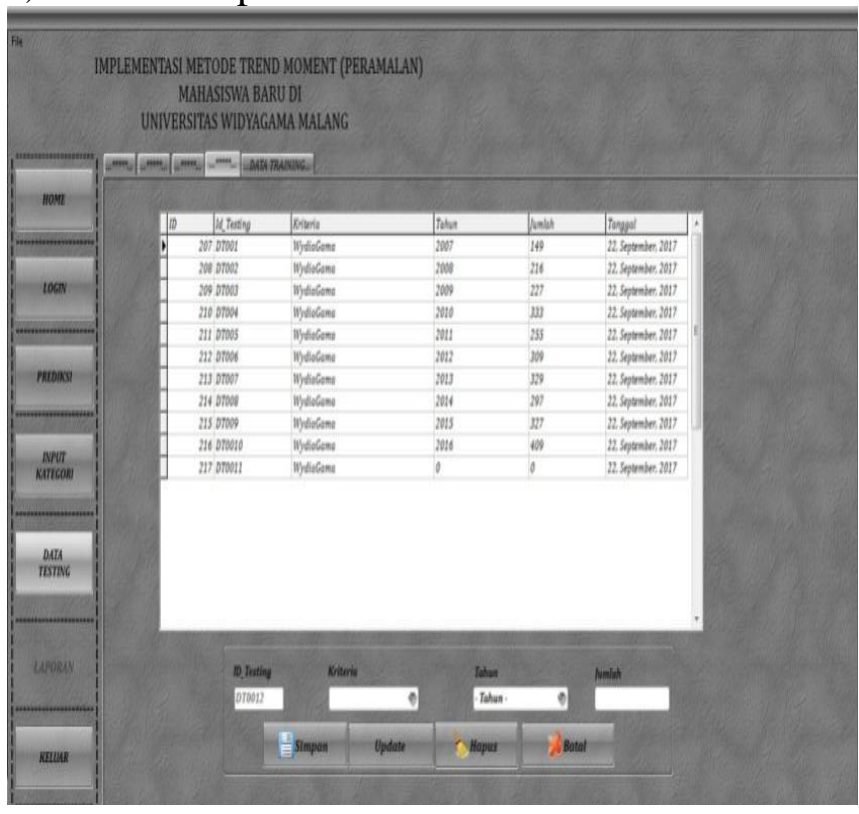

Gambar 13. Implementasi form data prediksi

Form data testing menampilkan data testing. Didalam menu input testing ini dapat menyimpan data, mengupdate data, menghapus data dan membatalkan data. Data testing ini berisi data-data mahasiswa di tahun yang berbeda dan data testing menunjukkan jumlah data mahasiswa yang ada

\section{5) Form laporan}

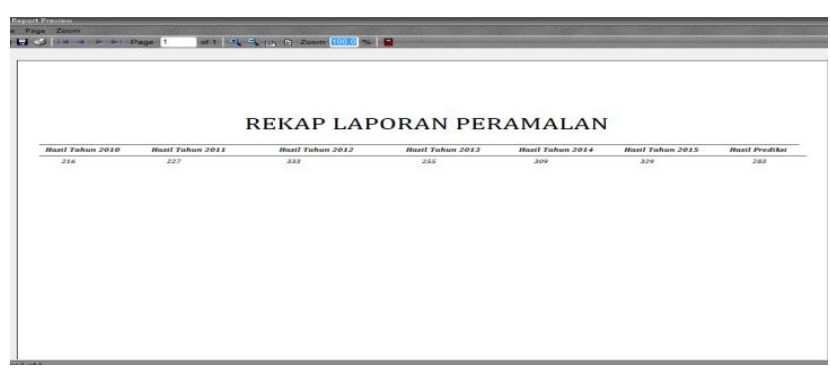

Gambar 14. Form laporan

Form laporan ini merupakan rekap laporan data hasil prediksi permalan jumlah mahasiswa 10 tahun mendatang

\section{KESIMPULAN DAN SARAN}

Berdasarkan dari hasil penelitian, analisis, perancangan sistem dan pembuatan program sampai tahap penyelesaian aplikasi, maka penulis dapat mengambil kesimpulan. Aplikasi permalan menggunakan metode tren moment dapat dipergunakan untuk meramalkan jumlah mahasiswa baru universitas widyagamamalang diperiode akan datang. Aplikasi peramalan ini dapat mempermudah petugas di universitas widyagama malang untuk menentukan dan mengetahui jumlah mahasiswa baru yang akan datang. Tingkat kesalahan dari sistem aplikasi ini menggunakan nilai perbandingan hasil peramalan dengan hasil data real. Dimana perhitungan menggunakan sample nilai 2 tahun kebelakang dengan menggunakan nilai perbandingan tahun 2016 dan tahun 2017 sebanyak 638 dan 485 dengan nilai hasil peramalan tahun 2018 dan tahun 2019. Dalam kasus ini sistem memiliki tingkat akurasi sebanyak 98, $25 \%$.

Guna terciptanya Aplikasi Metode Trend Moment (peramalan) Mahasiswa baru di universitas widyagama malang diharapkan adanya pengembangan sistem ini menjadi bentuk website maupun kedalam bentuk android. Dengan berbasis website, maupun android pengguna jika ingin melakukan diagnosa dapat dilakukan dimana aja dan kapan saja.

\section{DAFTAR PUSTAKA}

[1] Y. H. Peng, C. S. Hsu, and P. C. Huang, "An investigation of spacial approaches for crop price forecasting in different Taiwan markets," TAAI 2015 2015 Conf. Technol. Appl. Artif. Intell., pp. 176-179, 2016.

[2] J. A. Awan and D. H. Bae, "Application of Adaptive Neuro-Fuzzy Inference System for dam inflow prediction using long-range weather forecast," 8th Int. Conf. Digit. 
Inf. Manag. ICDIM 2013, pp. 247-251, 2013.

[3] W. Guan et al., "Advanced Load Forecast with hierarchical forecasting capability," IEEE Power Energy Soc. Gen. Meet., 2013.

[4] N. Cao, J. J. Huang, and X. M. Xie, "Study and application of dynamic collocation of variable weights combination forecasting model," Proc. - 2013 IEEE 11th Int. Conf. Dependable, Auton. Secur. Comput. DASC 2013, no. 1, pp. 404-409, 2013.

[5] J. Schachter and P. Mancarella, "A short-term load forecasting model for demand response applications," Int. Conf. Eur. Energy Mark. EEM, 2014.

[6] V. Kontorovich, "Efficient multi-moment non-linear filtering: experimental study for low power chaotic signals *," pp. 0-5, 2014.

[7] A. Biswas, G. Lin, X. Liu, and H. W. Shen, "Visualization of Time-Varying Weather Ensembles across Multiple Resolutions," IEEE Trans. Vis. Comput. Graph., vol. 23, no. 1, pp. 841-850, 2017.

[8] T. Kobayashi, S. Muramatsu, and H. Kikuchi, "2-D NON-SEPARABLE GENLOT WITH TREND VANISHING MOMENTS Dept . of Electrical \& Electronic Engineering, Niigata University,” Design, pp. 385-388, 2010. 